\title{
La edición genética en embriones humanos y sus implicaciones en la salud.
}

Salus 2021; 25(2):42-46.

Genetic editing in human embryos and its health implications.

Juan Manuel Alba Bermúdez' (D) Catherine M. Armijos Gómez²

https://doi.org/10.54139/salus.v25i2.62

\section{RESUMEN}

Introducción: Con el descubrimiento de la técnica CRISPR-Cas9 para corregir errores en el genoma se ha abierto la posibilidad de realizar modificaciones en embriones humanos.

Desarrollo: Con dicho procedimiento se puede liberar a futuros bebés de enfermedades por daños en el ADN, como por ejemplo la distrofia muscular de Duchenne. A pesar de ello, el planteamiento genera un enfrentamiento ideológico entre dos corrientes ideológicas que exponen sus argumentos en contra y a favor de dicha práctica

Conclusiones: Es evidente que la tecnología crece a un ritmo sin precedentes y es por ello, que debemos estudiar las posibles soluciones a la luz de la bioética, con el objetivo de hallar respuestas a los innumerables interrogantes que subyacen para la salud de las personas.

Palabras clave: Edición genética, embriones, CRISPR-Cas9, bioética.
${ }^{1}$ Universidad de Las Américas Facultad de Derecho. Quito-Ecuador.

${ }^{2}$ Universidad de Las Américas, facultad de Biotecnología. Quito-Ecuador

Autor de correspondencia: Juan Manuel Alba Bermúdez ${ }^{1}$ (iD

E-mail: juanmanuel.alba@udla.edu.ec

Recibido: 04-03-2020

Aprobado: 01-08-2021
Introduction: With the discovery of the CRISPR-Cas9 technique to correct errors in the genome, the possibility of making modifications in human embryos has opened up.

Development: With this procedure, future babies can be freed from diseases caused by DNA damage, such as Duchenne muscular dystrophy. Despite this, the approach generates a confrontation between two ideological currents with arguments against and in favor of this practice.

Conclusions: It is evident that technology is growing at an unprecedented rate and that is why we must study possible solutions from a bioethics perspective, with the aim of finding answers to the innumerable questions that underlie people's health.

Key words: Genetic editing, embryos, CRISPR-Cas9, bioethics.

\section{INTRODUCCIÓN}

La edición genética de embriones humanos hace referencia al proceso por el cual el genoma es editado mediante técnicas moleculares como la reciente CRISPR. Su finalidad es generar un embrión libre de algún padecimiento y que ese cambio sea heredable en sucesivas generaciones. Es necesario realizar una reflexión detallada de los aspectos éticos, políticos, jurídicos $y$, especialmente, los posibles efectos en la salud de los participantes (1).

A finales del 2018, el científico He Jiankui anunció el nacimiento de los primeros bebés genéticamente modificados que dieron lugar al nacimiento de dos gemelas. La noticia tuvo una repercusión mundial y un impacto mediático en la mayoría de los centros y comités de investigación. Precisamente el realizar cambios heredables y permanentes en los genes de un embrión humano e implantarlo posteriormente ha ocasionado un dilema moral sin precedentes que es objeto de estudio en la mayoría de los países occidentales.

La problemática no reviste tanto interés por las técnicas utilizadas sino por las futuras consecuencias que el mismo traería en el desarrollo y la salud de las niñas. El presente ensayo tiene como objetivo explicar los problemas y posibles soluciones ante de abrir las puertas a la modificación genética en embriones humanos. 
PROBLEMAS ÉTICOS Y SOCIALES. Las preocupaciones éticas y sociales respecto al uso de CRISPR, particularmente en embriones humanos, surgieron hace algunos años, específicamente cuando la bioquímica Doudna y el Instituto de Berkeley para la innovación del Genoma de la Universidad de California convocaron una reunión en el californiano Valle Napa. Una vez allí, los catorce directores invitaron a los mayores expertos científico en la temática, así como a ganadores de varios Premios Nobel. La discusión del evento se centró en la modificación de la línea germinal y se concluyó que el uso de la técnica CRISPR con la finalidad de crear bebés se prohíbe rotundamente. De tal forma que recomendaron que las implicaciones sociales, ambientales y éticas de dicha actividad deben ser estudiadas al máximo nivel de su capacidad. Además, se estableció la necesidad de fomentar investigaciones transparentes para poder evaluar la eficacia y especificidad de la tecnología de ingeniería del genoma por medio de CRISPR-Cas9 en modelos humanos (2).

Recientemente se consagró la iniciativa de la edición del Genoma Humano (3) liderada por la NAS de Estados Unidos, la NAM, Royal Society del Reino Unido y la Academia China de Ciencia que, por unanimidad establecen que las investigaciones de línea germinal son un acto irresponsable. Sin embargo, recomiendan la autorización de la investigación cuando: 1) se haya logrado resolver los problemas de seguridad y eficacia sobre los riesgos, beneficios potenciales y alternativas $y, 2$ ) exista un amplio consenso social sobre la idoneidad de la aplicación (4). Por el momento se puede asegurar que los criterios establecidos no se han cumplido puesto que los problemas de seguridad no se han explorado adecuadamente. Así, muchos países contemplan en sus ordenamientos jurídicos la prohibición expresa de la modificación de la línea germinal en seres humanos (5).

A inicios del 2017 la NAS (National Academy of Sciences) (6) y NAM (National Academy of Medicine) (7) convocaron una Cumbre con veintidós especialistas bioéticos con el objetivo de crear un informe denominado "Día de San Valentín". Dicho documento abarcaba temas tan controversiales como la investigación básica y la edición de la línea germinal para la mejora de seres humanos. El Informe sostiene que la edición de la línea germinal sólo debe permitirse si se los realiza dentro de un marco regulatorio que incluya los siguientes criterios: 1) ausencia de alguna otra alternativa razonable, 2) prevenir una afección o enfermedad grave, 3) restricción a la edición de genes que predisponen fuertemente el padecimiento de la enfermedad, 4) disponibilidad de datos preclínicos o clínicos relevantes sobre los riesgos y beneficios, 5) supervisión continua y rigurosa durante el proceso, además de seguridad para todos los individuos implicados en el proceso, 6) transparencia con la privacidad de los resultados obtenidos, y finalmente (7) evaluación continua de los riesgos para la salud individual y para la sociedad (8). En resumen, se puede decir que la edición del genoma para fines que no sean la prevención de enfermedades o discapacidades no tiene justificación por el momento (9)

Por otra parte, en el Reino Unido se estableció en el Consejo de Nuffield (10), un grupo de bioética sin fines de lucro que emitieron dos informes altamente importantes basados en la edición del genoma y la reproducción humana. En ellos, se concluyeron que las intervenciones del genoma para influir características de futuras generaciones podría ser éticamente aceptable si cumple con los siguientes requisitos y recomendaciones (que se sobreponen a las establecidas en el Informe del Día de San Valentín) (11): 1) Ser destinado a asegurar el bienestar de la persona que pueda nacer como consecuencia de dichas intervenciones, 2) manifestar coherencia de manera social, es decir no debe esperarse que genera una desventaja o discriminación en la sociedad, 3) recomendar la realización de investigaciones sobre la edición del genoma para poder establecer estándares para el uso clínico, 4) potenciar que los diferentes gobiernos del Reino Unido colaboren con instituciones internacionales de Derechos Humanos como la UNESCO y el Consejo de Europa, con la finalidad de promover el diálogo y generar un marco para la gobernanza internacional de las intervenciones de la edición del genoma, 5) las intervenciones del genoma solo deben ser autorizadas si se encuentran sujetas a la correcta evaluación de riesgos adversos para la persona futura y una estricta supervisión de los efectos hacia la persona después de nacer. El citado Consejo es primordial y de gran ayuda para la comunidad científica al permitir la investigación más a fondo sobre esta situación, siempre y cuando se precautele la salud de los implicados.

ARGUMENTOS EN CONTRA.En los últimos años cualquier avance científico ha sido susceptible de análisis y debate con relación a la diversidad de argumentos tanto a favor como en contra. Los grandes retos y complejos desafíos actuales en el ámbito científico pasan obligatoriamente por la adopción de estrategias orientadas a la cooperación internacional.

La investigación científica es la base de cualquier avance -de relevancia- que se produzca es el fruto de un trabajo colaborativo de investigadores multidisciplinares (12).

El primer argumento hace referencia a que la modificación de embriones es peligrosa al considerarse irreversible $y$, además, es una experimentación insegura hasta el momento (13). El autor Jean-Marc Daran, señala que como en muchos organismos, los humanos contienen dos copias de cada cromosoma, es decir una proveniente a

\section{Salus Revista de la facultad de ciencias de la Salud. Universidad de Carahobo. Mayo/agosto 2021 Vol. 25 № 2}


partir de cada padre. Por lo tanto, estas copias van a tener diferencias que es lo que producirá las variaciones genéticas entre los individuos. Por ello, cuando se utiliza CRISPRCas9 para dirigir el mecanismo hacia un solo cromosoma en organismos heterocigotos como lo son los humanos se activará un mecanismo de reparación natural. De manera general este mecanismo utiliza la otra copia del cromosoma como plantilla para poder reparar el ADN.

De tal forma que al aplicar la técnica de CRISPR-Cas 9 se espera que la célula repare el ADN utilizando la nueva cadena de material genético, así se introducirá nuevos genes de especial interés. No obstante, la probabilidad que el ADN repare la nueva cadena es prácticamente bajo e incierto, por lo que el proceso de edición no tendrá ningún éxito (14). Esta edición indeseable podría conducir a la pérdida de la heterocigosidad del organismo (15) y producirse un desequilibrio alélico donde una célula somática heterocigótica se vuelve homocigótica debido que pierde uno de sus dos alelos.

De hecho, la inestabilidad cromosómica puede ser considerado una ventaja de crecimiento selectivo que podría generar consecuencias extremadamente graves e impredecibles para la salud. Un ejemplo de ello se encuentra en los genes causantes de enfermedades como el cáncer que se encontraban latentes (alelos recesivos). Por tanto, si deseamos realizar la técnica de manera eficiente es apuntar a ambos cromosomas simultáneamente y así solo sea necesario modificar uno.

En la misma línea argumentativa, el científico Gang Bao, centra sus trabajos en los tratamientos de edición génica para la enfermedad de células falciformes. Sus estudios demuestran el elevado riesgo de utilizar dicha técnica, ya que, existen demasiadas incógnitas en su aplicación con seres humanos.

Para ilustrarlo, la técnica de CRISPR-Cas9 es parecida a un bisturí que será colocada en una célula y generará cortes cerca de los defectos que se desean modificar para después ser reemplazados por el segmento deseado que funcione correctamente.

A pesar de ello, dicho procedimiento también puede cortar otros genes de manera impredecible lo que podría generar un cambio de función en algún gen que cause alguna enfermedad (16). Incluso si la edición de genes sea de manera precisa, los "efectos fuera del objetivo" (del inglés off targets effects), podrían influir de manera significativa en la función de muchos genes dentro del organismo provocando así nuevos problemas en la salud (Figura 1) (17).

\section{Off-target effects}

The Cas 9 protein works like a pair of molecular scissors. A guide RNA sequence binds to a complementary DNA sequence that is adjacent to a string of letters known as the proto-spacer adjacent motif (PAM). But there can be many sites in the genome that contain the same or similar sequences, so Cas 9 might cut in the wrong places.

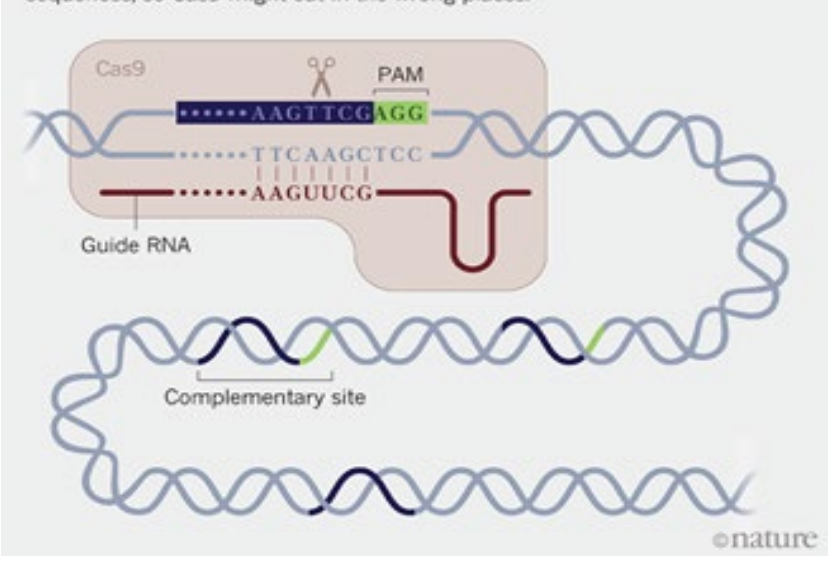

Tomado de Ledford H (17).

Figura 1. Off target effects resultados de la técnica CRISPR-Cas9

Otro posible inconveniente es que, en la línea germinal, estos efectos podrían persistir por generaciones y provocar cambios del genoma humano a largo plazo (18). Tanto es así que existen estudios que demuestran la activación de los oncogenes que inician la formación de células tumorales en los animales, así como, la función genética (fenotipo) de las plantas (19). En definitiva, hasta que no se conozca todas las consecuencias, o al menos una gran mayoría, es un craso error modificar la línea germinal en seres humanos, pues las consecuencias para la salud son impredecibles.

Otro de los principales argumentos en oposición es la existencia de científicos sin escrúpulos y dispuestos a cualquier acuerdo. Por todos es sabido que la tecnología CRISPR-Cas9, al poseer componentes sencillos y básicos, se pueden adquirir de manera muy fácil al no requerir mayores conocimientos científicos. Lamentablemente, en internet se pueden adquirir los reactivos para la edición del genoma y en plataformas como YouTube se encuentran videos explicativos para realizar los procesos de protocolos, denominado do it yourself de la edición génica. Por eso, la enorme reticencia de sectores de la sociedad a dicho procedimiento.

El siguiente razonamiento estriba en la ausencia de consentimiento informado (20) Al no existir la manifestación expresa de una persona que. mediante sus capacidades mentales, físicas y morales pueda manifestar una decisión de participar voluntariamente- en una investigación. No se contempla la posibilidad de participar en una investigación después de comprender toda la información que se le ha brindado incluyendo los objetivos, beneficios y posibles riesgos, así mismo los derechos y responsabilidades (21). 
Francis Collins indica que "los problemas éticos que se presentan al alterar la línea germinal que afectaría a la próxima generación no sería dable si no existe un consentimiento". Cuando se decide sobre la vida de un individuo completamente independiente al de sus progenitores se está violando de cierta forma el principio de autonomía. En ausencia de consentimiento informado prevalece la decisión de los padres y no es baladí que los cambios heredables generarian problemas de salud a sus descendientes (22).

En la misma línea se encuentra la tecnología privilegiada al considerar que buscar un hijo podría ocasionar privilegios a solo una pequeña parte de la población puede acceder (23). Tal es el caso de la terapia génica, cuyo propósito es resolver la deficiencia de lipasa lipoproteica (enfermedad hereditaria) caracterizada por hipertigliceridemia severa y riesgo de pancreatitis.

La terapia génica AAV1-LPLS447X se basa en la adición de dos copias epizonales de genes LPL funcionales en las células musculares para así mejorar la función metabólica o restaurarla por completo, pero tiene un coste económico de casi un millón dólares de los Estados Unidos de Américas (24). Entonces, al presentarse la nueva opción de crear hijos a la medida correríamos el riesgo de convertir la sociedad en un campo elitista de batalla, y no solo por el poder adquisitivo, sino por los privilegios de la genética (25).

Por eso, los escenarios transhumanistas nos vaticinan un futuro incierto y sombrío con relación a los límites de la investigación.

Finalmente, el biólogo David King declara que cuando comience a crear una sociedad donde los niños obtengan beneficios biológicos sobre otros niños, las nociones básicas sobre la igualdad humana desaparecerán. Además, indica que existirá una desigualdad económica con el sistema CRISPR-Cas9 que convertirá a los "bebés fabricados" en un producto disponible únicamente para la gente que tenga los recursos necesarios (26). Se generará un momento donde las personas serán emprendedoras, inteligentes, carismáticas o socialmente más hábiles que otras solo por el dinero que poseen. De tal forma, que todo ello provocará un sistema donde las personas pudientes económicamente podrán comprar ventajas sobre sus hijos.

ARGUMENTOS A FAVOR. Por otra parte, encontramos variados argumentos a favor del uso de la mencionada tecnología. Entre ellos, los científicos defienden la posibilidad de hallar la solución a diversas enfermedades por medio de la edición génica. Es así como, Eric Olson, indica que es de gran relevancia utilizar la modificación genética en caso de que se trate de trastornos monogénicos como la distrofia muscular de Duchenne. El científico sostiene que los beneficios van a superar abismalmente a los riesgos, al aclarar que la edición genética por medio de CRISPR-Cas9 sería capaz de eliminar potencialmente la causa subyacente de los trastornos monogénicos (27) (alelo), al igual, que errores del ADN.

Se señala la necesidad de apuntalar e incrementar las investigaciones antes de ser aplicada en seres humanos (28). De la misma manera, el profesor Eric Topol, establece que la edición del genoma aplicado CRISPR es de gran utilidad para enfermedades que no tienen terapia efectiva. Añade el autor que dicha estrategia es recomendable para el estudio de enfermedades como el cáncer mediante la aceleración del sistema inmunitario editando las células $T$ del paciente. Por ende, concluye que el equilibrio entre el beneficio y el riesgo para tratar dichos trastornos es favorable a diferencia de las incógnitas de editar los embriones humanos (29).

La siguiente defensa estriba en el hecho de que dos tercios de los embriones humanos no logran desarrollarse con éxito al presentar algún tipo de complicación que podría evitarse, donde la mayoría de ellos se producen en el primer mes de embarazo (30). Cada año 7.9 millones de niños $(6 \%$ del total) nacen con algún defecto grave de origen $100 \%$ genético total o parcial y que se debe conocer sobre todos los posibles riesgos que pueda generar esta técnica y tomar en cuenta el sufrimiento de las personas que nacen con enfermedades como la de Huntington (31) (condición autosómica dominante, donde una copia del gen (HTT) alterado en cada célula resulta suficiente para poder causar el trastorno).

De la misma manera, la importancia del consentimiento informado adquiere un segundo plano, ya que la potestad de elección se le otorga al representante legal. Es evidente, que el menor de edad al someterse a un tratamiento de quimioterapia no puede tener rasgos de autodeterminación, lo cual, le impedirá tomar sus propias decisiones, delegando dicha responsabilidad a sus tutores legales (32). Dicho argumento se replica y justifica en la modificación genética.

POSIBLES SOLUCIONES PLANTEADAS. A raíz de lo analizado, se demuestra que la ciencia no se detiene y seguirá en continuo progreso. Sin duda, es una buena noticia, siempre y cuando vaya de la mano con la ética y el derecho. La edición génica es el presente y debemos plantear respuestas con el propósito de evitar el menor daño posible, conocido como la no-maleficencia.

La experiencia nos indica la necesidad de incorporar en el debate a un conjunto de expertos: científicos, juristas, filósofos, políticos y representantes de la sociedad civil. De igual forma, los científicos tienen la responsabilidad de explicar periódicamente las investigaciones que están realizando de manera entendible $y$, por otro lado, los políticos deben proporcionar los espacios necesarios para debatir los temas expuestos, con el objetivo de garantizar el bien común, a saber, la salud.

No se deberá obviar que cualquier tratamiento que incida en la vida de los seres humanos se someta a las pruebas 
de eficacia y seguridad. En el supuesto caso de aplicar la técnica, debe existir transparencia -objetividad- en los resultados obtenidos, con el objetivo de garantizar la salud de los participantes.

\section{DISCUSIÓN}

En definitiva, como se la tecnología CRISPR-Cas9 tiene importantes beneficios para la ciencia, así como numerosos interrogantes con relación a su utilización y las implicaciones para la salud de los participantes.

Entonces, antes decidir, se deberá tener en cuenta todas las implicaciones que la misma conlleva, así como la necesidad de aportar información objetiva, veraz y transparente a la sociedad civil siempre con el propósito de regular su uso en el supuesto caso de necesidad. Asimismo, debe señalarse la importancia de realizar un estudio conjunto (multidisciplinar) con el objetivo de encontrar respuesta a numerosas preguntas que aún quedan en el aire.

Desde el punto de vista ético, no es incorrecto hacer algo y tampoco abstenerse de hacerlo. Sin embargo, con el deseo de evitar un colapso argumentativo se debe repensar la moral (reflexión). Así, los científicos deberán usar la tecnología de forma responsable, siempre y cuando, las técnicas demuestren ser segura y efectiva en la salud de los participantes y sus futuros descendientes.

\section{REFERENCIAS BIBLIOGRÁFICAS}

1. Vicente $\mathrm{V}$. La revolución de la edición genética mediante crispr-cas 9 y los desafíos éticos y regulatorios que comporta. Cuadernos de bioética. 2016; 27: 223-239.

2. Fredrickson D. Asilomar: the end of the beginning. En: The recombinant DNA controversy. The National Academies Press. Washington 2014.

3. Chial H. DNA Sequencing technologies key to the human genome project. Nature Education. 2008; 44: 219-225.

4. Kalil T, Wadia C. Materials genome initiative for global competitiveness. [Consulta: 22/06/2020].

5. De Miguel I; Armaza E. Un análisis ético de las nuevas tecnologías de edición genética: el CRISPR-Cas9 a debate. Anales de la Cátedra Francisco Suárez; 2018; 52: 179-200. DOI: https://doi.org/10.30827/acfs.v52i0.6555

6. Halpern J. The U.S. National Academy of Sciences—In service to science and society. PNAS. 1997; 94 (5): 1606-1608.

7. National Academy of Medicine. [Publicación en línea]. About The National Academy of Medicine. [Consulta: 22/08/2020].

8. National Academies of Sciences, Engineering and Medicine. Heritable Genome Editing, en Human Genome Editing. The National Academies Press. Washington 2017; p. 111-136.

9. Jiménez González J. El Convenio de Oviedo y su adecuación a las nuevas técnicas de intervención del genoma humano. Bioderecho.es 2019; (10): 18 págs. https://doi.org/10.6018/ bioderecho. 430781

10. Wiley J. The Nuffield Council on Bioethics. The Nuffield council on bioethics. Qual Assur J 2006;10: 121-124. DOI: 10.1002/ qaj.364
11. Greely H. CRISPR'd babies: Human germline genome editing in the "He Jiankui affair. J Law Biosci 2019.

12. González G, Ferri J. La colaboración científica: principales líneas de investigación y retos de futuro. Rev Español Doc Cient 2014; 37(4): e062. https://doi.org/10.3989/redc.2014.4.1186

13. Chávez P. Lecturas del principio de precaución en el debate actual sobre el estatuto ético del embrión humano. Dilemata. 2013; 11: 113-125.

14. VanDijk T. Beer yeast and the dangers of modifying human embryos. Disponible en: https://www.delta.tudelft.nl/article/ beer-yeast-and-dangers-modifying-human-embryos\#

15. Schwarzenbach H. Loss of Heterozygosity. Elsevier. 2013; 5 (3): 271-273.

16. Burgio G. What are off-target effects of CRISPR and why are they concerning? 2019; Nov.27 [Consulta: 24/12/2020]. Disponible en: https://www.biotechniques.com/crispr/what-areoff-target-effects-and-why-are-they-concerning/

17. Ledford H. CRISPRbabies: when will the world be ready? Nature 2019; 570:293-296.

18. Bao G. Gene editing for treatments for sickle cell disease. Ash Publications. 2016; 128(22): 56-69.

19. Naeem H. Majeed S. Zahir M. Admad I. Latest developed strategies to minimize the off-target effects in crisprcasmediated genome editing. Cell. 2020; 9 (7):1608.

20. Mondragon-Barrios L. Consentimiento informado: una praxis dialógica para la investigación. Rev Invest Clin 2009; 61(1): 73-82.

21. Gil A, Lavilla P, Fernández E. El consentimiento informado en la investigación clínica. Anal Pediatr Cont 2003; 40 (3): 109-118.

22. Skerret P. A debate: Should we edit the human germline? 2015; Nov. 30. [Consulta: 14/11/2020].Disponible en: https://www. statnews.com/2015/11/30/gene-editing-crispr-germline/.

23. Alba, J. Análisis del término reproducción asistida. Rev. derecho genoma hum. 2017: 45-57.

24. Gaudet D. Gene therapy for lipoprotein lipasae deficiency. curr opin lipidol. 2012; 23(4): 310-320.

25. Pueblo, C. Construyendo al hijo perfecto: Diseño de bebés. [Consulta: 23/06/2020].

26. Chalom O. Genetic Editing: Ethical and Social Issues. [Consulta: 18/06/2020].

27. Bastiaansen J, Bovenhuis $\mathrm{H}$. The impact of genome editing on the introduction of monogenic traits in livestock. Genet Sel Evol. 2018; 50 (18): 1-14.

28. Terry S. Should CRISPR be used to edit human genes to treat genetic diseases? 2019; Feb 23 . [Consulta: 15/06/2020]. Disponible en: https://magazine.jhsph.edu/2019/should-crisprbe-used-edit-human-genes-treat-genetic-diseases

29. Alsaigh T, Nicholson L, Topol E. What should clinicians do to engage the public about gene editing?. AMA J Ethics. 2019;21(12):E1089-1097. doi: 10.1001/amajethics.2019.1089.

30. Harris J. Pro and Con: Should gene editing be performed on human embryos? 2016; Jul. 15.[Consulta:13/06/2020]. Disponible en: https://www.nationalgeographic.com/magazine/ article/human-gene-editing-pro-con-opinions

31. U.S National Library of Medicine. Huntington Disease. [Consulta: 22/08/2020].

32. Macías A. El consentimiento informado en Pediatría. Rev Cuba Pediatr 2006; 63 (1): 25-33. 